\title{
Preliminary needs assessment of mobile technology use for healthcare among homeless veterans
}

D Keith McInnes, Gemmae M Fix, Jeffrey L Solomon, Beth Ann Petrakis, Leon Sawh, David A Smelson

BACKGROUND: Homeless veterans have complex healthcare needs, but experience many barriers to treatment engagement. While information technologies (IT), especially mobile phones, are used to engage patients in care, little is known about homeless veterans' IT use. This study examines homeless veterans' access to and use of IT, attitudes toward health-related IT use, and barriers to IT in the context of homelessness. METHODS: Qualitative interviews were conducted with 30 homeless veterans in different housing programs in Boston, MA, ranging from emergency shelters to supportive transitional housing that allow stays of up to 2 years. Interviews were conducted in person, audio recorded and then transcribed. Three researchers coded transcripts. Inductive thematic analysis was used. RESULTS: Most participants $(90 \%)$ had a mobile phone and were receptive to IT use for health-related communications. A common difficulty communicating with providers was the lack of a stable mailing address. Some participants were using mobile phones to stay in touch with providers. Participants felt mobile-phone calls or text messages could be used to remind patients of appointments, prescription refills, medication taking, and returning for laboratory results. Mobile phone text messaging was seen as convenient, helped participants stay organized because necessary information was saved in text messages. Some reported concerns about the costs associated with mobile phone use (calls and texting), the potential to be annoyed by too many text messages, and not knowing how to use text messaging. CONCLUSION: Homeless veterans use IT and welcome its use for health-related purposes. Technology-assisted outreach among this population may lead to improved engagement in care. 


\section{Authors:}

2 D. Keith McInnes ${ }^{1,2}$

3 Gemmae M. Fix ${ }^{1,2}$

4 Jeffrey L. Solomon ${ }^{1}$

5 Beth Ann Petrakis ${ }^{1}$

6 Leon $\mathrm{Sawh}^{3,4,5}$

7 David A. Smelson $1,3,4$

8

$9 \quad{ }^{1}$ Department of Veterans Affairs, Edith Nourse Rogers VA Hospital, Bedford, MA

$10{ }^{2}$ Department of Health Care Policy, Boston University School of Public Health, Boston, MA

$11{ }^{3}$ VA National Center on Homelessness among Veterans, Philadelphia, PA and Bedford, MA

$12{ }^{4}$ Department of Psychiatry, University of Massachusetts Medical School, Worcester, MA

13 5school of Criminology and Justice Studies, University of Massachusetts, Lowell MA

18 Key Words: homeless persons, access to care, veterans, cellular phone, informatics, 


\section{INTRODUCTION}

The health of homeless veterans is among the worst of any vulnerable group, which is concerning given that there are approximately 49,900homeless veterans on the $\operatorname{street}^{1}$ and homeless veterans comprise $11 \%$ of the US homeless population. ${ }^{2}$ Homeless veterans have high rates of chronic conditions. A study of urban homeless veterans receiving care in a Department of Veterans Affairs (VA) medical center found 53\% suffering from degenerative joint disease or arthritis, $45 \%$ with hypertension, $35 \%$ with hyperlipidemia, and $28 \%$ with hepatitis. ${ }^{3}$ The study also reported that mental health related conditions were highly prevalent, with $71 \%$ suffering from alcohol use disorder, $67 \%$ with depressive disorders, $43 \%$ cocaine use disorder, $37 \%$ anxiety disorders, $17 \%$ opioid use disorder, and $11 \%$ bipolar disorder.

Information technologies (IT) are increasingly being used to improve access to health care, make utilization of services more efficient, and improve health outcomes. ${ }^{4,5}$ IT such as mobile phone tools including texting and apps contribute to improved medication adherence, ${ }^{6}$ increased clinic attendance rates, ${ }^{7}$ increased vaccination rates, ${ }^{8}$ and behavior changes such as reduction in smoking in non-homeless populations. ${ }^{9}$ And there is early stage research into the use of mobile phone apps to promote substance use harm reduction and abstinence. ${ }^{10}$ Survey data from 2010 indicate $71 \%$ of veterans use the internet and $20 \%-25 \%$ use the VA's electronic personal health record system (PHR). ${ }^{11}$ While some of this research examines use of information technologies with people with low incomes in low resource settings, such as in developing countries, there have been few interventions aimed at assisting homeless persons in their use of technologies for health-related purposes. Data from primarily non-veteran populations indicate that about half or more of homeless persons have mobile phones. ${ }^{12-14}$ Therefore, we sought to understand 
42 homeless veteran's access to and use of information technologies, and whether using these

43 technologies to communicate with health care providers would be acceptable to them. While we sought information on a wide range of technologies (e.g. computer, mobile phone, internet), special attention was given to the topic of mobile phones, for two reasons: first, the growing literature indicating that persons who are homeless have access to that technology more than others, ${ }^{14-16}$ and second, the VA's development of a patient-provider text messaging system for chronic disease management. ${ }^{17}$ This system could be a promising means of improving patientprovider communication and addressing chronic health conditions in homeless veterans.

Veterans are an important group to study because of the multiple opportunities to engage them in their health care through existing and developing information technologies, such as the My HealtheVet personal health record system used by 1.8 million veterans, ${ }^{18}$ and the coming national patient-provider text messaging system. ${ }^{17}$ Though the study sample is veterans, there are reasons to believe that lessons learned will be transferable to non-veteran homeless populations.

Both populations share many of the same health care needs, barriers to health care services, and challenges accessing information technologies. ${ }^{11,19,20}$ Our research questions were, 1) How accessible are information technologies (e.g. computers, internet, and mobile phones) to homeless Veterans?, and, 2) What level of interest do homeless veterans have in using

59 information technologies to communicate with healthcare providers? METHODS

61 The current qualitative study was one component of a larger survey project that examined rates

62 of technology ownership among 106 homeless veterans living in an urban area of the Northeast

63 US. $^{21}$ In the current study we used a qualitative approach that was based on grounded theory. ${ }^{22}$

64 This involved inductive analysis and coding that used the constant comparative method, ${ }^{23}$ with 
an emphasis on allowing the emergence of themes from the data. In-depth interviews were conducted with 30 homeless veterans to explore access to, and perceptions of, information technologies; and, attitudes toward using information technologies for health related purposes.

Participants. We sought to represent a variety of homeless veterans by recruiting from different geographic locations and housing programs around the greater Boston metropolitan area. Thus our sample represents an urban population. Our target was to interview 20 subjects, expecting that would achieve theoretical saturation. ${ }^{24}$ Additionally we wanted diversity of subjects that might be enhanced by recruiting subjects from four different types of housing programs. We sought to interview a minimum of five per organization, but were inclined to have larger numbers, if feasible, because this would add to our knowledge of the different types of housing programs and potential roles they played in facilitating or impeding the residents' use of information technologies. At each of the organizations we exceeded our targets because staff facilitated the recruitment and interview process, for example by making 2 interview rooms available for the researchers. The 30 veterans recruited came from five locations representing four different types of housing programs - domiciliary, transitional housing, grant-per-diem (GPD), and emergency shelter (we recruited from two shelters that were in adjoining towns, but run by the same organization). Two housing programs (domiciliary and transitional housing) were run by the US Department of Veterans Affairs (VA) and two by a single local non-profit organization (GPD and the two emergency shelters). The VA Domiciliary program has a maximum 100 day stay with a focus on veterans with substance use disorders, while the VA transitional housing program allows residence for up to two years. GPD refers to housing owned by a non-profit, with maintenance and program costs partially subsidized by federal funding. 
Residents in the GPD program described in this study can stay for up to two years and they receive supportive services including case management and vocational training. Sampling from these different programs was intended to provide representation of a variety of health care and other needs. Emergency shelters, for example, tend to serve persons with fewer connections to services and more unstable lives, ${ }^{25}$ while GPD programs typically require more evidence that a person has made substantial progress in recovery from substance use and has more supportive services that help maintain stability. ${ }^{26,27}$

Researchers met with staff at the four programs to describe the study objectives and to enlist staff assistance in notifying residents about the study. In addition, at the domiciliary and the transitional housing facilities, investigators described the study directly to residents at the weekly resident meetings and posted flyers about the research study. There was no attempt to oversample women or racial/ethnic minorities. Interviews were conducted between January and September 2012 at the program facilities. Prior to the interviews, a qualitative team investigator (GF) conducted training for interviewers (BAP, KO, DKM) on semi-structured interviewing techniques and taking field notes.

Written informed consent was obtained from all participants prior to the interviews. Participants received \$25 for study participation. The study conforms to the Declaration of Helsinki ethical principles and was approved by the Institutional Review Board of the Edith Nourse Rogers Memorial Veterans Hospital, Bedford, Massachusetts (Approval \#0008). 
110 Data collection. We conducted semi-structured qualitative interviews. In addition to collecting

111 demographic and health information, interview topics covered two broad areas, first, access to

112 IT, including ownership of a mobile phone, use of mobile phones, uses of other information

113 technologies (e.g. computer, Internet), and information technology use related to health care; and

114 secondly, perceptions of potential health-related interventions based on mobile phone calls or

115 texting, such as reminders (e.g. for appointments, medication-taking and refills, reminders,

116 availability of lab results). Interviewers recorded descriptive field notes immediately following

117 interviews, using a template designed to capture detailed information about the interview that

118 would be available for discussion by the team at weekly meetings. ${ }^{28}$ The template had the

119 following categories: overview (e.g., general impressions, interview rapport), description of

120 participant (e.g., affect, how dressed), highlights (memorable parts of the interview), key

121 thoughts about technology and interventions (e.g., how might a health information technology

122 intervention work for someone like this), life issues, barriers and facilitators (both to information

123 technologies and to healthcare). Completing the notes was done in conjunction with listening to

124 the audio. The field notes included quotes or paraphrases (and minute marker so that it would be

125 easy to find the quote on the audio). These detailed field notes both helped to capture

126 information about the interview that is not picked up well by audio (e.g. perceptions of mood or

127 personality of the respondent) and provided the first step in the analysis process, without having

128 to wait for all audio recordings to be transcribed. In addition verbatim interview transcripts were

129 created and used by the research team to extract participant quotes to augment what was in the

130 field notes. 
132 Analysis. An analysis team (BAP, JS, KM) led by a qualitative research expert (JS) conducted

133 an inductive thematic analysis to identify broad themes and subthemes from the field notes. ${ }^{29}$

134 Investigators used an iterative process to develop a preliminary list of themes and to develop

135 inter-rater reliability. Each member conducted a close reading of seven field notes and coded

136 them for preliminary themes. Through in-person meetings the team developed consensus on the

137 list of themes. Then, using a set of 5 field notes, team members did coding, compared coding

138 results, discussed differences and came to consensus about the codes, as a means of achieving

139 inter-rater reliability. Meetings were used to discuss those themes, determine whether they

140 indicated the emergence of additional themes, and make a revised list of themes. Through

141 subsequent meetings some themes were collapsed and new themes were added. The remaining

14218 field notes were divided among the analysis team for coding, with investigators meeting

143 regularly to discuss the coding process and any potential new themes. Throughout these

144 discussions, investigators maintained a strong degree of consensus regarding the themes. Themes

145 and corresponding examples from field notes were documented and tracked in a shared folder

146 accessible to the analysis team.

147

148 Once all field notes had been coded in the shared coding document, each member of the analysis

149 team developed a written summary of the most salient themes. Salience was defined both by

150 frequency of codes supporting that theme and/or the degree that it addressed study goals. We

151 met to discuss the written summaries and come to consensus on the most important findings. In

152 a final phase, after developing preliminary interpretations, we searched the data for alternative

153 interpretations and rival conclusions. 
RESULTS

Description of participants. The 30 participants ranged in age from 33 to 65 years. Most (87\%) were male and white (77\%). Other race/ethnicities were black (17\%) and Native American (7\%). Over half (60\%) had some college education (but not 4-year degrees), 37\% had completed high school or equivalent, and 3\% had not completed high school. Almost all (90\%) had a mobile phone at the time of the interview, $70 \%$ used the Internet, and $72 \%$ had an email address. See Table 1. Of the cell phones, 30\% were smartphones. When asked about current health, commonly mentioned conditions were depression, PTSD, substance and alcohol use disorders, anxiety, and hepatitis C.

165

Overview of findings. We have organized our findings into four main areas: 1) Barriers to communication with health care providers; 2) Access and barriers to, and current use of, information technologies, in general; 3) Current uses of information technologies for healthrelated purposes; and, 4) Attitudes toward information technology use for new types of health-

170 related communications. Related to the fourth theme (attitudes toward information technology), 171 our interview questions covered specific uses of IT for appointment reminders, medication refill 172 reminders, medication adherence support, and laboratory result notification - all of which have 173 been tried in the general population, but not with homeless persons. Findings from each of the 174 four main areas are described below.

175

\section{Barriers to communication with health care providers.}


177 Becoming homeless creates substantial disruption in a person's life that can be long lasting.

178 Communication with health care providers and systems becomes complicated. Some reported

179 that they no longer had a reliable mailing address, or the health system had an old address on file

180 and letters were going to that address. Thus they sometimes missed important letters containing

181 medical appointment reminders or changes, or laboratory results. Similarly, most no longer had

182 a landline phone as a result of their homelessness, causing them to miss telephone appointment

183 reminders from their healthcare providers. Cell phones replace landlines, but participants staying

184 in shelters reported that guests must hand in their mobile phones to staff in the late afternoon or

185 evening for safekeeping overnight.

186

187

188

189

190

191

192

194

195

196

197

198

199

\section{Access and barriers to, and current use of, information technologies, in general.}

Information technologies (e.g. computers, mobile phones, tablets) were used by almost all study participants. They used these devices for many of the same reasons that non-homeless persons do, such as staying in touch with family and friends, taking care of personal business (e.g. making appointments, checking bank accounts, connecting with health care providers), entertainment, and gathering information, including, to some extent, health-related information.

Mobile phones. Ninety percent of participants had mobile phones. Participants paid for the devices and service in a number of ways. Some got their phones through government programs that provide a free device and 250 free minutes per month, with some respondents noting they had 2 such free phones in order to boost the number of monthly available minutes. Others had inexpensive devices and bought pre-paid cards (e.g. $\$ 10$ or $\$ 20)$ for phone and/or texting services and reloaded cards as needed. Others were on contracts. Typically this was through a 
relative, friend, spouse, or ex-spouse. Mobile phones were used for things like keeping in touch with family and friends, tracking appointments on the calendar feature, and searching for work. A number reported they used texting, while others did not, but indicated they would like to learn

203 how.

Computers and internet. Use of computers, the internet, and email were common. A few had laptops, while others reported using computers at libraries and other locations that provided free computer and internet access. Common uses were for reading the news, searching for jobs, and entertainment, such as listening to music and playing games. Some used the Internet to find places to stay. A few reported not knowing how to use the internet and similarly not having an email account. However, there was interest among these respondents in learning how to use the

211 internet.

212

\section{Current uses of information technologies for health-related purposes.}

General uses. Many participants were using computers, Internet, and mobile phones for healthrelated purposes. Table 2 summarizes our findings related to perceptions and use of IT for health-related purposes. Some seemed to regularly use their mobile phones to keep in touch with primary care and other health care providers, including psychiatrists, social workers, and case managers.

"I'd be lost [without my cell phone]...I keep in close communication with my social worker, for my doctors, and everything. They always check on me..." 
223 A few used mobile phone text messaging to contact health care providers, including to find out

224 about upcoming appointments. Many respondents used the internet to look up information about

225 medical conditions, medications, side effects, and medication interactions. Some used email to

226 check upcoming appointments with health care providers. Few respondents reported ever having

227 used an electronic personal health record (PHR), which, in the VA, is called My HealtheVet.

228 One reported using the My HealtheVet PHR to order medication refills and to check laboratory

229 results, and several others knew about the My HealtheVet PHR but had not used it. Quite a few

230 had never heard of it.

231

232

Appointment reminders, medication refill reminders, medication adherence, and laboratory.

233 Respondents were asked about whether they currently received reminders via mobile phone or

234 Internet, about appointments, medication refills or medication taking, or if they received

235 notification that laboratory results were ready. Some respondents currently received phone call

236 reminders and liked them. There was variation in what kind of phone calls the respondents liked.

237 Several liked live (e.g. speaking directly to receptionist or nurse) reminders because they were

238 seen as more personal and allowed patients to ask questions. Several respondents received

239 automated calls, or "robo-calls", but they generally were not satisfied with them. They reported

240 they could be confusing, for example it would not be clear to which clinic or doctor the

241 appointment was for, and there was often no phone number given to call back. None were

242 currently receiving regular text message reminders for health related purposes.

244 No respondents reported receiving systematic reminders to refill a prescription or to take a dose

245 of a current medication. Laboratory results, respondents reported, were generally given to them 
246 in-person when they came for health care visits. Respondents did not report receiving mobile

247 phone calls or text messages to let them know their laboratory results were ready.

\section{Attitudes toward information technology use for new types of health-related} communications.

We explored with participants a variety of ways that healthcare providers might use mobile phones to communicate with patients. We asked respondents about their interest in receiving 1) appointment reminders, 2) medication-related reminders, 3) notifications that laboratory results were ready, and 4) "checking-in" type outreach (either daily phone calls or texts to ask "how are you", or phone calls or text messages to patients who had not been seen in the clinic in a long time to encourage them to come for a visit). There was considerable support for healthcare providers using mobile phone technology to communicate with veterans for these kinds of purposes.

Appointment reminders. There was strong interest in receiving appointment reminders from healthcare providers (Table 3). Many respondents cited poor memory as one of the reasons that reminders were appealing. “A lot of us vets our memories aren't that great and to receive something on a cell phone wouldn't forget about it. Yeah, that would be very helpful." 
268 Perhaps because of the familiarity with this mode (some used to receive phone call reminders on

269 landlines), there was considerable openness to greater use of mobile phone call reminders. As

270 mentioned above, several preferred live phone calls which were viewed as more personal and

271 allowed greater interactivity, even if they cost more than a text message or an automated call,

272 "It's just more personal and you can ask questions". Automated calls, while acceptable to

273 some, were viewed more ambiguously by many others. Some referred to them disparagingly as

274 "robo-calls".

275

When you answer it you can't shut it off and you're stuck with it and it eats up all your time and you don't know who it is.

278

279

Also, others noted automated calls can be confusing because they often do not indicate who is calling, which doctor's office it is coming from, or which clinic to go to, and they often do not provide a phone number to call if one has questions.

Mobile phone text message reminders were seen as practical and efficient. Respondents liked the fact that they provide a written record that one can review as many times as needed. If English is not the recipient's first language, noted one respondent, the recipient can show the text message to a friend for help in understanding the message content. 
291 Conversely, a provider or receptionist may have an accent that is hard to understand, as noted

292 one respondent, and a text message would be preferable to voice communication that the patient

293 has a hard time understanding.

295 Participants liked the asynchronous nature of texting. One reported that he was not supposed to

296 receive phone calls during work, but with text messages he could read and respond to them

297 during breaks or after work. Other respondents suggested that text message reminders should

298 have the option for the recipient to respond, for example to confirm they will attend the

299 appointment, or to request rescheduling or cancellation.

300

301 Some in our sample were not sure of the value of text message appointment reminders. Some

302 did not want to receive any reminders (phone or text) on their mobile phone because of the cost.

303 Others were concerned about the potential annoyance of receiving too many text reminders,

304 while others reported they did not view their text in-box frequently enough for it to be valuable

305 as a reminder system for appointments coming in the next one to two days. Some respondents,

306 who lacked skills or confidence in texting, felt they would need to learn to use it because it was a

307 technology that, as one respondent said, is "here to stay". 
309

310

311

312

Medication related reminders. Participants were asked about two kinds of medication-related reminders - for prescription refills and for medication adherence. Medication refill reminders were generally positively seen, whether it was a live person making the reminder call, an automated call, or a text message. Several participants expressed interest in reminders to assist with medication adherence (Table 3 ).

Participants were generally in favor of receiving mobile phone calls - live or automated - to remind patients that it was time to refill a prescription. Here a respondent describes his preference for live calls for appointment reminders, "It's just more personal and you can ask questions. It's more informative, just better to talk to a live person."

There was also widespread support for text message reminders for medication refills.

Respondents proposed other ideas as well. One suggestion concerned hospital pharmacies. When patients were on-site at the hospital or medical center waiting for their medication, the pharmacy could text the patient that their prescription was ready to be picked up at the pharmacy window. This would allow patients to leave the pharmacy waiting room to go to other parts of the medical center, e.g. to cafeteria or store. Several respondents were supportive of text messages used for medication taking, for example the sending of text messages each morning at a specific time to remind a patient to take their pills.

Some respondents expressed concern about potentially receiving too many medication-related reminders. Some said it would be annoying to receive reminders daily or more often, for example before each dose of medication. 
If they do [text messages] more than once I would get annoyed. You know, ... if they do it like four, five times ... I'll probably throw the phone up against the wall!

Laboratory results. Participants felt it would be valuable to be notified via their mobile phone

337

338

that laboratory results were ready to be discussed with a healthcare provider, though this support was not as strong as for appointment reminders (Table 3). While several liked this idea, some were not interested because the current system of receiving lab results from their clinician during office visits worked fine for them, while others felt a text message saying their lab results were ready would just make them feel nervous that the results were going to be bad. Similar to appointment reminders, there was support, however, for text message reminders to have lab work done:

[Text messages to remind you to have lab work done] would be very helpful because they usually schedule [lab work] like months in advance. And if you don't write it down on the calendar and you try to remember something like that, it's impossible. So that would be a very good idea.

Caring Outreach. We explored the idea of a check-in or caring outreach, by phone call (live or automated) or text message. One type of message would target patients who had not been seen by their healthcare team in a long time, for example one or two years. The content of such a phone or text outreach was described as, "We were wondering how you are doing because we 
354 haven't seen you in a while? It would be great to see you. Please call $\mathrm{xxx}-\mathrm{xxx}-\mathrm{xxxx}$ to set up an

355 appointment". Respondents supported this idea (Table 3).

356

357 Interviewers also asked about daily outreach efforts delivered via mobile phone, such as "Are 358 you doing alright today?" This was also seen positively. Respondents indicated this would be 359 especially valuable for people who were having psychological difficulties.

360

That would be a huge help and then if you say, "no," [I'm not doing well] well okay then they transfer you and then either you're texting or phoning with somebody to try to help get you immediate help. Yeah that would be huge.

\section{DISCUSSION}

Through qualitative interviews with 30 homeless veterans living in a large Northeastern US metropolitan area, we found that the majority had access to, and used, mobile phones and other information technologies regularly, and also reported positive attitudes about health providers using these technologies to connect with homeless veterans related to their healthcare needs. Respondents viewed reminders especially favorably whether for upcoming health appointments, medication refills, medication taking, or to receive laboratory results. There was also support for mobile phone calls or text messages to reach out to individuals whose health was considered at especially high risk.

Life is disrupted when one does not have a stable home and this interrupts health seeking

376 behavior. ${ }^{30,31}$ While some homeless shelters have clinics on site, or facilitate transportation to 
377 health care services, in general the US health care system, including the VA health care system,

378 is designed for people who have stable housing, a dependable mailing address, a landline phone,

379 and easy access to the Internet. Homeless veterans lack many of these resources. However,

380 despite the economic, societal, situational and psychological barriers that affect homeless

381 veterans accessing healthcare, our results suggest that IT such as mobile phones can contribute to

382 improving access to outpatient health care services, which in turn may lead to improved health

383 outcomes. While these technologies may not directly address these serious underlying

384 challenges, IT does make it easier to connect with health care providers (e.g. text messages,

385 mobile phone calls, emails and secure messages), remember appointment times (e.g. using

386 calendar and reminder functions on one's phone, or receiving text message reminders from

387 health care team), and know when it is time to refill a medication (interactive voice response,

388 text messages or email refill reminders).

389

390 Treatment engagement is an area that can be addressed through mobile technologies as missed

391 visits and being lost to follow up present a significant problem for managing chronic conditions,

392 including homeless persons trying to manage high-risk health care needs such as HIV, substance

393 abuse, chronic pain, and depression. ${ }^{32-39}$ Fortunately, there is evidence that even modest

394 interventions can help improve visit attendance for vulnerable populations, including brochures

395 and posters in exam and waiting rooms reminding patients about the importance of coming to all

396 clinic visits, ${ }^{40}$ and text message appointment reminders which have been shown to increase

397 appointment attendance in a variety of health care settings with diverse populations. ${ }^{7}{ }^{41}$ Our

398 finding that many homeless persons use mobile phones suggests this may be a worthwhile

399 approach to reducing missed visits in that population. While text messaging to patients is not 
400

401

402

403

404

405

406

407

408

409

410

411

412

413

414

415

416

417

418

419

420

421

422

currently approved in VA health care, there is a VA texting system in development. ${ }^{17}$ Data such as presented in this study can encourage the more rapid spread of the system and provide some insights into how it might be used with certain veteran populations.

Another area ripe for innovations is medication adherence. Poor medication adherence is a serious barrier to chronic disease management, ${ }^{42}$ and low income populations are at especially high risk for non-adherence. ${ }^{43}$ Studies of homeless populations' medication adherence indicate that both patients and providers recognize it is a major problem. ${ }^{38}$ In a study of homeless and unstably housed tuberculosis patients, $36 \%$ reported they expected to have difficulty regularly taking their tuberculosis medications, and 30\% said they had no one to help remind them to take medications. ${ }^{44}$ This illustrates the lack of social support networks available to many homeless and unstably housed persons, and the potential role that IT, such as texting, emails, and social media, can play in creating an electronically enhanced social network or system that can support disease self-management. A number of studies in non-homeless populations, including randomized trials, have indicated that text message medication adherence reminders contribute to improved anti-retroviral medication adherence and reductions in viral load for persons with HIV ${ }^{6}$ Other studies have shown that text messaging interventions can contribute to other behavior changes, such as smoking cessation, $, 4,45,46$ blood glucose monitoring by diabetics, ${ }^{47}$ and weight loss behaviors. ${ }^{48}$ While our respondents reacted favorably to the idea of mobile phone medication-related reminders, they warned against over-utilization of such reminders. Once-a-day text-messages seemed to be the maximum acceptable number for medication adherence reminders and other health-related purposes. 
423 It is important to underscore that the use of IT with vulnerable populations is not without

424 challenges. With a low-income population such as the homeless, cost will inevitably be an issue

425 - some of our study participants felt that things like appointment reminders would be a waste of

426 their monthly allotment of talk and text. Other barriers for this population and include the

427 difficulty keeping phones charged, ${ }^{49}$ loss and theft of phones, ${ }^{50}$ and, for those in some emergency

428 shelters, not having access to mobile phones in the evenings because shelters lock up the phones

429 at night. Mental health and substance use disorders, highly prevalent among homeless

430 populations, may also contribute to barriers to health IT use. For example MH and SUD

431 conditions may interfere with remembering to purchase more minutes or to recharge a phone

432 battery. They may also interfere with income earning and thus lead to diminished financial

433 resources to buy computers and other devices, or to pay monthly internet and phone plan fees. A

434 broader health system issue regarding mobile phone texting relates to privacy. Some health care

435 settings, including the Department of Veterans Affairs, have not approved mobile phone texting

436 because it is considered unsecure. ${ }^{51}$ These systems hope to avoid inadvertent disclosure of

437 sensitive information, for example a patient sending a text message to a provider asking when

438 HIV test results would be ready would be exposing him/herself to loss of privacy. ${ }^{52}$

441 There are several limitations to this study. As a small study, using a convenience sample of

442 homeless veterans from a single metropolitan area, the findings may not be generalizable to other

443 populations of homeless veterans in other parts of the country, in rural areas, or to non-veterans.

444 That said, there are many similarities between veteran and non-veterans who are homeless in

445 terms of their health, health care needs, and utilization of services, though some research 
446 indicates morbidity may be greater in homeless veterans than in homeless non-veterans. ${ }^{19}$

447 Additionally, we did not interview any homeless veterans living on the streets, living doubled-up

448 with friends or relatives, or using single-room occupancy hotels. Based on results from studies

449 of non-veterans, ${ }^{12,16}$ we suspect we would find that veterans living on the streets are less likely

450 to own information technologies, and for those that do they likely experience more barriers to

451 regular use of those technologies (e.g. device not charged, lack of internet access, lacking phone

452 minutes). In addition, most participants were males, so the findings may not apply to women.

453 All data collected was via self-report, so the various uses of IT were not verified in an objective

454 manner. Social desirability bias may have caused respondents to speak more favorably of

455 proposed uses of technologies than they actually felt.

456

457 Conclusion: Many homeless veterans have mobile phones and regularly access the internet.

458 Mobile phones may represent an effective tool for communicating with homeless persons and

459 increasing their engagement in care and adherence to treatment. When asked about a variety of

460 kinds of communication, there was support for mobile phone calls and text messages, for

461 purposes such as appointment reminders, medication refill reminders, and reminders to take

462 medications. There was also support for outreach to bring back into care homeless patients who

463 had not been seen by their providers in a long time. Additional research is needed to evaluate

464 implementation of mobile phone communication systems for homeless persons in clinical

465 settings and to assess their impact on engaging homeless persons in health care services.

466 Mobile technologies may have certain advantages for this population, but PHRs also have

467 the potential to be useful. Further research should examine, for example, the effectiveness of

468 peer-navigators who would help homeless persons access PHRs by providing mini-trainings, 
469 technical support, and encouragement to try additional features. This could happen at medical 470 centers - especially ones that have clinics that target homeless patients, or in other places that 471 internet-connected computers are available such as in some shelters, transitional housing, and 472 libraries.

It is important to recall that among persons who are homeless there is a substantial

burden of chronic physical and mental health conditions; many in this population would benefit from more frequent assistance from the health care system. Their current situation of housing instability, however, interferes with access to and utilization of needed health services.

Innovative uses of technologies are needed that are acceptable to persons who are homeless,

behaviors, processes, and outcomes. Technologies that can increase patient chronic disease self-

mental health therapy are needed. Technologies, for example, can support better adherence to live therapeutic support based on the individual needs and preferences of patients.

Acknowledgements. We thank Kathryn O'Connor for help conducting interviews. The views expressed in this article are those of the authors and do not necessarily reflect the position or policy of the Department of Veterans Affairs or the US government.

\section{REFERENCES}

491 1. US Department of Housing and Urban Development. 2014 Annual Homeless Assessment Report 492 (AHAR) to Congress, part 1. Washington, DC

493 2. Perl L. Veterans and Homelessness. Washington, DC: Congressional Research Service; 2011 
494

495

496

497

498

499

500

501

502

503

504

505

506

507

508

509

510

511

512

513

514

515

516

517

518

519

520

521

522

523

524

525

526

527

528

529

530

531

532

533

534

535

536

537

538

539

540

541

3. O'Toole TP, Buckel L, Bourgault C, Blumen J, Redihan SG, Jiang L, Friedmann P. Applying the chronic care model to homeless veterans: effect of a population approach to primary care on utilization and clinical outcomes. American journal of public health. 2010;100(12):2493-2499

4. Free C, Phillips G, Galli L, Watson L, Felix L, Edwards P, Patel V, Haines A. The Effectiveness of Mobile-Health Technology-Based Health Behaviour Change or Disease Management Interventions for Health Care Consumers: A Systematic Review. PLoS Med. 2013;10(1)

5. Cole-Lewis H, Kershaw T. Text messaging as a tool for behavior change in disease prevention and management. Epidemiol Rev. 2010;32(1):56-69

6. Lester RT, Ritvo P, Mills EJ, Kariri A, Karanja S, Chung MH, Jack W, Habyarimana J, Sadatsafavi M, Najafzadeh M, Marra CA, Estambale B, Ngugi E, Ball TB, Thabane L, Gelmon L, Kimani J, Ackers M, Plummer FA. Effects of a mobile phone short message service on antiretroviral treatment adherence in Kenya (WelTel Kenya1): a randomised trial. Lancet. 2010;376(9755):1838-1845

7. Guy R, Hocking J, Wand $\mathrm{H}$, Stott $\mathrm{S}$, Ali H, Kaldor J. How effective are short message service reminders at increasing clinic attendance? A meta-analysis and systematic review. Health services research. 2012;47(2):614-632

8. Stockwell MS, Kharbanda EO, Martinez RA, Vargas CY, Vawdrey DK, Camargo S. Effect of a text messaging intervention on influenza vaccination in an urban, low-income pediatric and adolescent population: a randomized controlled trial. JAMA : the journal of the American Medical Association. 2012;307(16):1702-1708

9. Free C, Knight R, Robertson S, Whittaker R, Edwards P, Zhou W, Rodgers A, Cairns J, Kenward $M G$, Roberts I. Smoking cessation support delivered via mobile phone text messaging (txt2stop): a single-blind, randomised trial. Lancet. 2011;378(9785):49-55

10. Cohn AM, Hunter-Reel D, Hagman BT, Mitchell J. Promoting behavior change from alcohol use through mobile technology: the future of ecological momentary assessment. Alcohol Clin Exp Res. 2011;35(12):2209-2215

11. Tsai J, Rosenheck RA. Use of the internet and an online personal health record system by US veterans: comparison of Veterans Affairs mental health service users and other veterans nationally. Journal of the American Medical Informatics Association : JAMIA. 2012;19(6):1089-1094

12. Eyrich-Garg KM. Mobile phone technology: a new paradigm for the prevention, treatment, and research of the non-sheltered "street" homeless? J Urban Health. 2010;87(3):365-380

13. Stennett $\mathrm{CR}$, Weissenborn MR, Fisher GD, Cook RL. Identifying an effective way to communicate with homeless populations. Public Health. 2012;126(1):54-56

14. McInnes DK, Li AE, Hogan TP. Opportunities for engaging low-income, vulnerable populations in health care: a systematic review of homeless persons' access to and use of information technologies. American Journal of Public Health. 2013;103 Suppl 2:e11-24

15. Eyrich-Garg KM. Mobile phone technology: a new paradigm for the prevention, treatment, and research of the non-sheltered "street" homeless? Journal of urban health : bulletin of the New York Academy of Medicine. 2010;87(3):365-380

16. Eyrich-Garg KM. Sheltered in cyberspace? Computer use among the unsheltered 'street' homeless. Computers in Human Behavior. 2011;27:296-303

17. McInnes DK, Houston TK, Woods SS, Frisbee KL, Evans NC. Disseminating Information Systems across the Atlantic: Collaboration between U.K. National health Service and U.S. Department of Veterans Affairs. 7th Annual Conference on the Science of Dissemination and Implementation, December 8-9 Bethesda, MD; 2014

18. Nazi KM, Hogan TP, McInnes DK, Woods SS, Graham G. Evaluating patient access to Electronic Health Records: results from a survey of veterans. Medical care. 2013;51(3 Suppl 1):S52-56

19. O'Toole TP, Conde-Martel A, Gibbon JL, Hanusa BH, Fine MJ. Health care of homeless veterans. J Gen Intern Med. 2003;18(11):929-933 
20. Tsai J, Mares AS, Rosenheck RA. Do homeless veterans have the same needs and outcomes as non-veterans? Mil Med. 2012;177(1):27-31

21. McInnes DK, Sawh L, Petrakis BA, Rao S, Shimada SL, Eyrich-Garg KM, Gifford AL, Anaya HD, Smelson DA. The potential for health-related uses of mobile phones and internet with homeless veterans: Results from a multi-site survey. Telemed J E Health. 2014;(in press)

22. Glaser BG. The Future of Grounded Theory. Grounded Theory Review. 2000;1:1-8

23. Glaser BG. The Constant Comparative Method of Qualitative Analysis. Social Problems. 1965;4(Spring):436-445

24. Guest G, Bunce A, Johnson L. How many interviews are enough? An experiment with data saturation and variability. Field Methods. 2006;18(1):59-82

25. Petrovich JC, Pollio DE, North CS. Characteristics and service use of homeless veterans and nonveterans residing in a low-demand emergency shelter. Psychiatric services. 2014;65(6):751-757

26. Gabrielian S, Yuan AH, Andersen RM, Rubenstein LV, Gelberg L. VA health service utilization for homeless and low-income Veterans: a spotlight on the VA Supportive Housing (VASH) program in greater Los Angeles. Medical care. 2014;52(5):454-461

27. VA Homeless Providers Grant and Per Diem Program. Final rule. Federal register. 2013;78(37):12600-12617

28. Bernard HR. Research Methods in Anthropology: Qualitative and Quantitative Approaches. Walnut Creek, CA: Alta Mira; 2002

29. Patton M. Qualitative Research and Evaluation Methods, 3rd ed. Thousand Oaks, CA: Sage Publications, Inc.; 2002

30. Gelberg L, Gallagher TC, Andersen RM, Koegel P. Competing priorities as a barrier to medical care among homeless adults in Los Angeles. American journal of public health. 1997;87(2):217-220 31. O'Toole TP, Conde-Martel A, Gibbon JL, Hanusa BH, Freyder PJ, Fine MJ. Where do people go when they first become homeless? A survey of homeless adults in the USA. Health \& social care in the community. 2007;15(5):446-453

32. Giordano TP, Visnegarwala F, White AC, Jr., Troisi CL, Frankowski RF, Hartman CM, Grimes RM. Patients referred to an urban HIV clinic frequently fail to establish care: factors predicting failure. AIDS Care. 2005;17(6):773-783

33. Schluger N, Ciotoli C, Cohen D, Johnson H, Rom WN. Comprehensive tuberculosis control for patients at high risk for noncompliance. American journal of respiratory and critical care medicine. 1995;151(5):1486-1490

34. Karter AJ, Parker MM, Moffet HH, Ahmed AT, Ferrara A, Liu JY, Selby JV. Missed appointments and poor glycemic control: an opportunity to identify high-risk diabetic patients. Medical care. 2004;42(2):110-115

35. Macharia WM, Leon G, Rowe BH, Stephenson BJ, Haynes RB. An overview of interventions to improve compliance with appointment keeping for medical services. JAMA : the journal of the American Medical Association. 1992;267(13):1813-1817

36. Haynes RB, McDonald HP, Garg AX. Helping patients follow prescribed treatment: clinical applications. JAMA : the journal of the American Medical Association. 2002;288(22):2880-2883

37. Mugavero MJ, Westfall AO, Zinski A, Davila J, Drainoni ML, Gardner LI, Keruly JC, Malitz F, Marks G, Metsch L, Wilson TE, Giordano TP. Measuring retention in HIV care: the elusive gold standard. Journal of acquired immune deficiency syndromes. 2012;61(5):574-580

38. Hwang SW, Wilkins E, Chambers C, Estrabillo E, Berends J, MacDonald A. Chronic pain among homeless persons: characteristics, treatment, and barriers to management. BMC Fam Pract. 2011;12:73 39. Weiser SD, Riley ED, Ragland K, Hammer G, Clark R, Bangsberg DR. Brief report: Factors associated with depression among homeless and marginally housed HIV-infected men in San Francisco. $J$ Gen Intern Med. 2006;21(1):61-64 
40. Gardner LI, Marks G, Craw JA, Wilson TE, Drainoni ML, Moore RD, Mugavero MJ, Rodriguez AE, Bradley-Springer LA, Holman S, Keruly JC, Sullivan M, Skolnik PR, Malitz F, Metsch LR, Raper JL, Giordano TP. A low-effort, clinic-wide intervention improves attendance for HIV primary care. Clin Infect Dis. 2012;55(8):1124-1134

41. Mclnnes DK, Petrakis BA, Gifford AL, Rao SR, Houston TK, Asch SM, O'Toole TP. Retaining homeless veterans in outpatient care: a pilot study of mobile phone text message appointment reminders. American Journal of Public Health. 2014;104 Suppl 4:S588-594

42. Viswanathan M, Golin CE, Jones CD, Ashok M, Blalock SJ, Wines RC, Coker-Schwimmer EJ, Rosen DL, Sista P, Lohr KN. Interventions to Improve Adherence to Self-administered Medications for Chronic Diseases in the United States: A Systematic Review. Ann Intern Med. 2012

43. Mojtabai R, Olfson M. Medication costs, adherence, and health outcomes among Medicare beneficiaries. Health Aff (Millwood). 2003;22(4):220-229

44. Craig GM, Booth H, Story A, Hayward A, Hall J, Goodburn A, Zumla A. The impact of social factors on tuberculosis management. Journal of advanced nursing. 2007;58(5):418-424

45. Free C, Whittaker R, Knight R, Abramsky T, Rodgers A, Roberts IG. Txt2stop: a pilot randomised controlled trial of mobile phone-based smoking cessation support. Tob Control. 2009;18(2):88-91

46. Rodgers A, Corbett T, Bramley D, Riddell T, Wills M, Lin RB, Jones M. Do u smoke after txt? Results of a randomised trial of smoking cessation using mobile phone text messaging. Tob Control. 2005; 14(4):255-261

47. Hanauer DA, Wentzell K, Laffel N, Laffel LM. Computerized Automated Reminder Diabetes System (CARDS): e-mail and SMS cell phone text messaging reminders to support diabetes management. Diabetes Technol Ther. 2009;11(2):99-106

48. Patrick K, Raab F, Adams MA, Dillon L, Zabinski M, Rock CL, Griswold WG, Norman GJ. A text message-based intervention for weight loss: randomized controlled trial. J Med Internet Res. 2009;11(1):e1

49. Le Dantec CA, Edwards WK. Designs on dignity: perceptions of technology among the homeless. CHI '08: Proceedings of the SIGCHI conference on human factors in computing systems. 2008:627-636 50. Bure C. Digital inclusion without social inclusion: The consumption of information and communication technologies (ICTs) within homeless subculture in Scotland. The Journal of Community Informatics. 2006;2(2):116-133

51. Hassinen M, Laitinen P. End-to-end Encryption for SMS Messages in the Health Care Domain. Connecting Medical Informatics and Bio-Informatics: Proceedings of MIE2005 - The XIXth International Congress of the European Federation for Medical Informatics Amsterdam: IOS Press; 2005:316-321

52. Lim MS, Hocking JS, Hellard ME, Aitken CK. SMS STI: a review of the uses of mobile phone text messaging in sexual health. Int J STD AIDS. 2008;19(5):287-290

53. Burns MN, Begale M, Duffecy J, Gergle D, Karr CJ, Giangrande E, Mohr DC. Harnessing context sensing to develop a mobile intervention for depression. J Med Internet Res. 2011;13(3):e55 


\section{Table $\mathbf{1}$ (on next page)}

Characteristics of study participants 
1

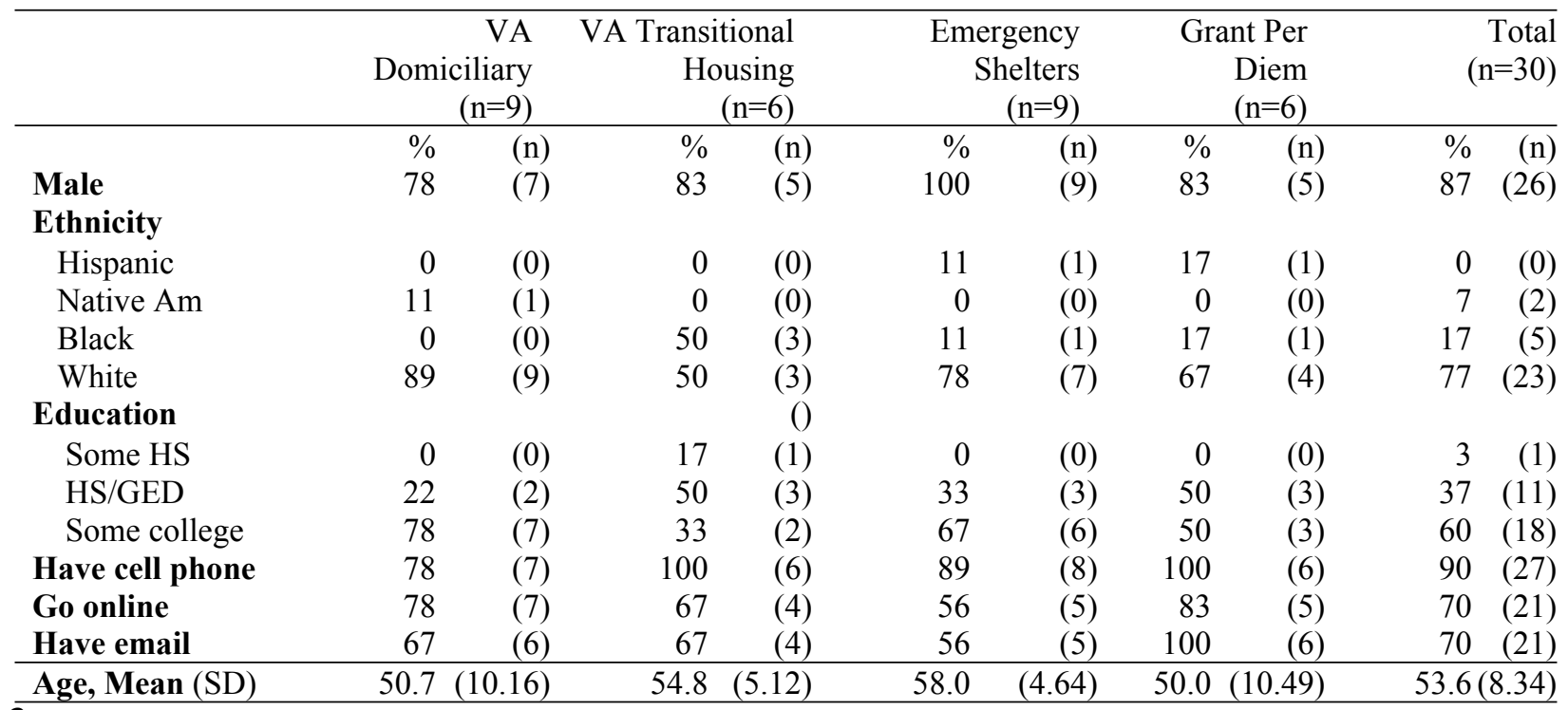

2 VA=Department of Veterans Affairs; $\mathrm{SD}=$ standard deviation; HS=high school; GED=high school equivalency exam 3 


\section{Table 2 (on next page)}

Perceptions and uses of IT for health-related purposes, summary of findings 


\begin{tabular}{|c|c|}
\hline Topic & Perceptions and Uses (exemplar quotes in italics) \\
\hline $\begin{array}{l}\text { Current health-related uses of } \\
\text { technology }\end{array}$ & $\begin{array}{l}\text { - Receive cell-phone reminder calls for appointments } \\
\text { - Use of mobile phone to stay in touch with health professionals } \\
\text { - Some reported dislike for automated appointment reminder calls which } \\
\text { can be confusing and use up valuable cell phone minutes. } \\
\text { "[When you receive an automated call]... you can't shut it off and } \\
\text { you're stuck with it and it eats up all your [phone minutes] and you } \\
\text { don't know who it is." }\end{array}$ \\
\hline Perceived benefits & $\begin{array}{l}\text { - Convenience: information is retrievable, there is less need to write } \\
\text { appointment information down, and the asynchronous communication } \\
\text { is less intrusive. } \\
\text { Well you have something solid in front of you. You don't have to } \\
\text { write it down. You can save it and it's there. I mean you have all } \\
\text { your information right there. } \\
\text { - Organization: reduces worry about losing slips of paper with } \\
\text { appointment information, and forgetting to go to appointments }\end{array}$ \\
\hline Possible barriers & $\begin{array}{l}\text { - Cost: calls and texts cost the recipient money if they do not have an } \\
\text { unlimited mobile phone plan } \\
\text { "[I wouldn't want cell phone reminders]...not with what it costs } \\
\text { me." } \\
\text { - Annoyance: too many text messages become annoying instead of } \\
\text { helpful } \\
\text { - Lack of skills: some participants lacked text messaging skills }\end{array}$ \\
\hline
\end{tabular}

2 


\section{Table 3(on next page)}

Attitudes toward specific health IT communication tools 


\begin{tabular}{|c|c|}
\hline Topic & Attitudes and Perceptions (exemplar quotes in italics) \\
\hline Appointment reminders & $\begin{array}{l}\text { Many were supportive of text messages used for appointments } \\
\text { Well you have something solid in front of you. You don't have to write it } \\
\text { down. You can save it and it's there. I mean you have all your information } \\
\text { right there. }\end{array}$ \\
\hline Medication-related reminders & $\begin{array}{l}\text { Support for parsimonious use of medication related-reminders } \\
\text { If they [send text messages] more than once I would get annoyed. You } \\
\text { know, ... if they do it like four, five times ... I'll probably throw the phone } \\
\text { up against the wall! }\end{array}$ \\
\hline $\begin{array}{l}\text { Notifications related to laboratory } \\
\text { work needed and results }\end{array}$ & $\begin{array}{l}\text { Support for text message reminders to get laboratory tests done } \\
\text { [Text messages to remind you to have lab work done] would be very helpful } \\
\text { because they usually schedule [lab work] like months in advance. And if } \\
\text { you don't write it down on the calendar and you try to remember something } \\
\text { like that, it's impossible. So that would be a very good idea. }\end{array}$ \\
\hline "checking-in" type outreach & $\begin{array}{l}\text { Proactive messages to patients not seen in clinic for a long time } \\
\text { That would be a huge help and then if you say, "no," [I'm not doing well] } \\
\text { well okay then they transfer you and then either you're texting or phoning } \\
\text { with somebody to try to help get you immediate help. Yeah that would be } \\
\text { huge. }\end{array}$ \\
\hline
\end{tabular}

